\title{
Tribolium castaneum como Modelo Experimental para Estudos em Metabolismo de Carboidratos e Lipídeos: uma prospecção tecnológica
}

\section{Tribolium castaneum as an Experimental Model for Studies of Lipid and Carbohydrates Metabolism: a technological prospection}

\author{
Meirielly Kellya Holanda Silva ${ }^{1}$ \\ Mariana Macêdo Costa Batalha ${ }^{2}$ \\ Camila Braga Dornelas ${ }^{2}$ \\ Luciano Aparecido Meireles Grillo \\ ${ }^{1}$ Universidade Federal de Alagoas, Arapiraca, AL, Brasil \\ ${ }^{2}$ Universidade Federal de Alagoas, Maceió, AL, Brasil
}

\begin{abstract}
Resumo
Neste artigo realizou-se uma prospecção tecnológica com o objetivo de analisar pedidos de depósitos de patentes referentes à utilização do Tribolium castaneum como modelo experimental para estudos em metabolismo de carboidratos e lipídios, por meio de patentes das bases de dados PatentScope e Espacenet, e artigos científicos da PubMed. A maioria dos pedidos de depósitos se refere a repelentes de pestes/controle de pragas, o que é explicado pelo fato de o Tribolium castaneum ser uma das principais pragas de grãos armazenados com distribuição mundial. Dessa forma, nenhum dos pedidos analisados se refere à sua utilização como modelo experimental para estudos em metabolismo de carboidratos e lipídios, assim como não se encontrou artigo científico explicitando seu desenvolvimento. Diante dessa lacuna, conclui-se que esta é uma área tecnológica pouco explorada e potencialmente útil para novas pesquisas e produtos.
\end{abstract}

Palavras-chave: Tribolium castaneum. Carboidratos. Lipídios.

\begin{abstract}
A technological survey was carried out aiming at analyzing patent filing requests regarding the use of Tribolium castaneum as an experimental model for studies in carbohydrate and lipid metabolism, through patents from the PatentScope and Espacenet databases, and scientific articles from PubMed. Most deposit orders refer to pest repellants/pest control, which is explained by the fact that Tribolium castaneum is one of the main stored grain pests with worldwide distribution. Thus, none of the analyzed applications refers to its use as an experimental model for studies in carbohydrate and lipid metabolism, as well as no scientific article was found explaining its development. In view of this gap, it is concluded that this is a technological area little explored and potentially useful for new research and products.
\end{abstract}

Keywords: Tribolium castaneum. Carbohydrate. Lipid.

Área Tecnológica: Utilização dos Animais. Metabolismo e Bioenergética. Saúde Pública. 


\section{Introdução}

Os insetos constituem a forma de vida animal mais abundante no planeta, com espécies organizadas em aproximadamente 800 famílias e distribuídas em 32 ordens, sendo o grupo mais numeroso o dos artrópodes, que compreendem cerca de $70 \%$ de todas as espécies animais conhecidos (HOY, 1994; CHOWANSKI et al., 2017). Um dos fatores de sucesso de adaptação dos insetos se baseia no fato de apresentarem metamorfose completa, ou seja, fases de ovo, larva, pupa e adulto (CISNE, 1974). Outro ponto é a presença de asas, possibilitando a conquista dos ambientes mais diversos, eficiência na busca do alimento, defesa contra predação, além de garantir o fluxo gênico das espécies através da migração (MARANHÃO, 1977; CHOWANSKI et al., 2017).

Várias pesquisas utilizaram insetos como modelos experimentais, as quais foram posteriormente observadas em mamíferos. Entre elas, pode-se destacar o processo de seleção natural observado em Biston betularia (FISHER, 1933); a identificação do processo de endocitose mediada por receptores (ROTH; PORTER, 1964; TELFER, 1960; 1961); a compreensão do mecanismo de ação de hormônios esteroidais por meio de experimentos com ecdisona (SCHELLER; KARLSON, 1977); a descoberta do citocromo c (KEILIN, 1966) e das secropinas e peptideos antibacterianos (BOMAN; HULTMARK, 1987); estudos com Drosophila melanogaster, realizados por meio da biologia molecular, identificaram-se genes "homeobox" responsáveis por determinar o padrão de organização dos eixos corporais e sua homologia com vertebrados (AKAM, 1989); e estudos genéticos e moleculares que apontaram os locais do Sistema Nervoso Central relevantes para comportamentos sexuais masculinos (DEMIR; DICKSON, 2005; SAKAI; KITAMOTO, 2006).

Dessa forma, vem sendo mais frequente a realização de estudos com a utilização de insetos como modelos experimentais alternativos, resultando em achados que possam ser reproduzíveis em vertebrados (INSUA et al., 2013). Assim, o Tribolium castaneum, importante praga de grãos armazenados, tem sido a segunda escolha como sistema modelo para estudos em insetos, ficando atrás apenas da mosca-da-fruta $D$. melanogaster, que lidera as pesquisas na área de genética (DÖNITZ et al., 2013).

O sucesso observado com a utilização do T. castaneum se deve à rápida reprodução, alta fecundidade, intervalos curtos de geração, baixos custos de manutenção, aspectos éticos aceitáveis, genoma acessível em banco de dados, além das sequências de genes apresentarem intensa relação de homologia com outras espécies, incluindo humanos, compartilhando com estes cerca de 126 grupos de genes ortólogos (RICHARDS et al., 2008).

Devido à alta homologia observada entre o T. castaneum e humanos e ao alto grau de conservação em sequências com domínios característicos de famílias de proteínas, muitos estudos têm sido realizados utilizando este inseto como modelo, como por exemplo, estudos de interação entre fatores nutricionais e expressão gênica, utilizando genes homólogos. A facilidade na incorporação de fatores nutricionais em sua alimentação o tem colocado como importante modelo para estudos deste tipo, constituindo uma alternativa importante para a diminuição do uso de animais em laboratórios para testes de screening (GRÜNWALD; STELLZIG; ADAM, 2013).

Uma pesquisa sobre o metabolismo lipídico de Rhodnius prolixus (GRILLO; MAJEROWICZ; GONDIM, 2007) elucidou pontos sobre o processo digestivo e o metabolismo de lipídios em insetos, inferindo que tais mecanismos ocorrem de forma análoga àquela dos mamíferos. Tal informação, associada às características específicas do Tribolium castaneum, colocam-no como 
modelo experimental ideal para estudos do metabolismo de lipídios e carboidratos. Dessa forma, este trabalho tem como objetivo realizar uma revisão patentária e bibliográfica, por meio de uma prospecção tecnológica, que correlacione a utilização do T. castaneum como modelo experimental para estudos do metabolismo de lipídeos e carboidratos.

\section{Metodologia}

Trata-se de uma pesquisa exploratória nas bases de dados de patentes World Intellectual Property Organization (WIPO - PatentScope) e Espacenet ${ }^{\circledR}$ (Banco Europeu de Patentes, Latipat), para delineamento do atual cenário tecnológico acerca da utilização do Tribolium castaneum como modelo experimental para estudos em metabolismo de lipídeos e carboidratos, sendo esta a tecnologia a que se refere tal prospecção. A busca foi realizada durante o período de 25 de junho a 10 de julho de 2019 e todas as etapas da análise foram realizadas por dois pesquisadores de forma independente, de modo a aumentar a fidedignidade e sensibilidade dos dados coletados. A partir das palavras-chave selecionadas, buscou-se por patentes e artigos científicos desde o primeiro registro até o ano de 2018.

Na base de dados PatentScope padronizou-se a busca pela marcação da opção "organismos - PCT" e com a utilização do campo "página de cobertura" para pedidos de depósito via PCT, em todas as línguas. Na base Espacenet utilizou-se o campo "busca avançada", procurando por palavras-chave no título e no resumo. Foi criado um banco de dados utilizando o software Excel ${ }^{\circledR}$ e para tabulação dos gráficos utilizou-se o software GraphPad Prism6 ${ }^{\circledR}$.

Para a revisão bibliográfica, foi realizada busca de artigos na base de dados PubMed, comparando os artigos dessa busca com os pedidos de depósito de patente via PCT na base PatentScope, tendo em vista sua maior abrangência. O operador boleano AND foi usado para indicar ao software a combinação de termos. As palavras-chave utilizadas nas bases de dados de patentes e artigos estão descritas na Tabela 1.

Tabela 1 - Palavras-chave utilizadas nas buscas de patentes e artigos

\begin{tabular}{cc} 
PatentScope, Espacenet e PubMed & EsPaCENET \\
Tribolium castaneum & Tribolium castaneum \\
Experimental model & Modelo experimental \\
Hypertriglyceridemia & Hipertrigliceridemia \\
Dyslipidemia & Dislipidemia \\
Hyperglycemia & Hiperglicemia \\
\hline
\end{tabular}

Fonte: Elaborada pelos autores deste artigo (2019) 


\section{Resultados e Discussão}

Os resultados para as buscas de patentes com pedido de depósito via PCT na base PatentScope e para as buscas de artigos científicos na base PubMed referentes ao termo Tribolium castaneum apresentaram-se similares, demonstrando consenso entre o interesse na produção científica e na tecnológica, como demonstrado na Tabela 2. O mesmo ocorre ao se correlacionar as palavras-chave "Tribolium castaneum AND experimental model", já que se observa similaridade entre o número de patentes e artigos, além dessa correlação demonstrar mais especificidade sobre o objeto de interesse. Diante de tais resultados, optou-se por realizar a busca nas bases de dados PatentScope e PubMed por meio dos termos "Tribolium castaneum AND experimental model", devido à sua maior especificidade.

Tabela 2 - Número de patentes e artigos obtidos a partir da busca com as palavras-chave selecionadas

\begin{tabular}{cccc} 
PalaVRAS-CHAVE & PATENTSCOPE & EsPaCENET & PuBMED \\
Tribolium castaneum & 1.155 & $\underline{05}$ & 1.379 \\
Experimental model & 140.419 & 00 & 1.849 .948 \\
Hypertriglyceridemia & 5.119 & 02 & 14.486 \\
Dyslipidemia & 8.119 & 04 & 91.956 \\
Hyperglycemia & 13.280 & 01 & 63.892 \\
Tribolium castaneum AND experimental model & $\underline{188}$ & $\underline{00}$ & $\underline{130}$ \\
Tribolium castaneum AND hypertriglyceridemia & 00 & 00 & 00 \\
Tribolium castaneum AND dyslipidemia & 00 & 00 & 00 \\
Tribolium castaneum AND hyperglycemia & 00 & 00 & 00 \\
Experimental model AND hypertriglyceridemia & 1.881 & 00 & 1.179 \\
Experimental model AND dyslipidemia & 3.173 & 00 & 7.667 \\
Experimental model AND hyperglycemia & 6.206 & 00 & 7.405 \\
\hline
\end{tabular}

Fonte: Elaborada pelos autores deste artigo (2019)

O resultado das buscas na base Espacenet com as palavras-chave em português apresentou maior especificidade, como apresentado na Tabela 3. Porém, ainda é possível observar que há diminuição acentuada no número de patentes com as palavras-chave Tribolium castaneum, quando comparada à base PatentScope; e ao se relacionar as outras palavras-chave, a busca é nula. Dessa forma, a análise na base Espacenet ocorreu utilizando-se os termos Tribolium castaneum e Modelo experimental, separadamente, como forma de contemplar o objetivo deste estudo. 
Tabela 3 - Número de patentes obtidas a partir da busca com as palavras-chave selecionadas

$\begin{array}{cc}\text { PalavRAS-CHAVE } & \text { ESPACENET } \\ \text { Tribolium castaneum } & \underline{05} \\ \text { Modelo experimental } & \underline{66} \\ \text { Hipertrigliceridemia } & 336 \\ \text { Dislipidemia } & 1.012 \\ \text { Hiperglicemia } & 428 \\ \text { Tribolium castaneum AND modelo experimental } & 00 \\ \text { Tribolium castaneum AND hipertrigliceridemia } & 00 \\ \text { Tribolium castaneum AND dislipidemia } & 00 \\ \text { Tribolium castaneum AND hiperglicemia } & 00 \\ \text { Modelo experimental AND hipertrigliceridemia } & 00 \\ \text { Modelo experimental AND dislipidemia } & 00 \\ \text { Modelo experimental AND hiperglicemia } & 00\end{array}$

Fonte: Elaborada pelos autores deste artigo (2019)

De acordo com a International Patent Classification (IPC), da WIPO, a tecnologia a que se refere esta prospecção pertence ao código C12N 15/06, como especificado na Tabela 4. Dessa forma, os pedidos de patentes serão analisados, além do quantitativo por ano e país requerente e de depósito, quanto à sua classificação IPC.

Tabela 4 - Códigos de patentes utilizados nesta prospecção

Códigos

C

C12

C12N

C12N 15/00

C12N 15/06
Classificação

Química e Metalúrgica

Bioquímica; Cerveja; Álcool; Vinho; Microbiologia; Enzimologia; Engenharia Genética ou de Mutação.

Micro-organismos ou Enzimas; Suas Composições (biocida, repelentes ou atrativos de pestes, ou reguladores do crescimento de plantas contendo micro-organismos, preparados medicinais, fertilizantes). Propagação, Conservação ou Manutenção de Micro-organismos; Engenharia Genética ou de Mutações; Meio de Cultura.

Mutação ou Engenharia Genética; DNA ou RNA concernentes à Engenharia Genética, Vetores; uso de seus hospedeiros.

Fonte: IPC e WIPO (2019)

\subsection{Análise das patentes depositadas via PCT na base de dados PatentScope}

Foram analisadas as 188 patentes depositadas via PCT com as palavras-chave "Tribolium castaneum AND experimental model", como apresentado na Tabela 2. Inicialmente, pôde-se observar que o montante de patentes depositadas desde 1985, onde se identificou o primeiro registro, até o ano de 2018, apresentou aumento considerável, demonstrando assim o crescente 
interesse em utilizar o T. castaneum como modelo experimental. É possível observar que 2017 foi o ano em que ocorreu a maior quantidade de depósitos, com 26 pedidos, seguido de 2016, 2018 e 2015 com 25, 24 e 19 depósitos, respectivamente. A partir de 2014 houve um crescente aumento no interesse pelo objeto de estudo, e este fato pode ser justificado pelo surgimento de uma onda tecnológica iniciada neste ano, ou seja, provavelmente uma mudança na metodologia e/ou nas tecnologias de produção tenha ocasionado tal ápice (Gráfico 1).

Gráfico 1 - Número de patentes por ano na base PatentScope com as palavras-chave "Tribolium castaneum AND experimental model"

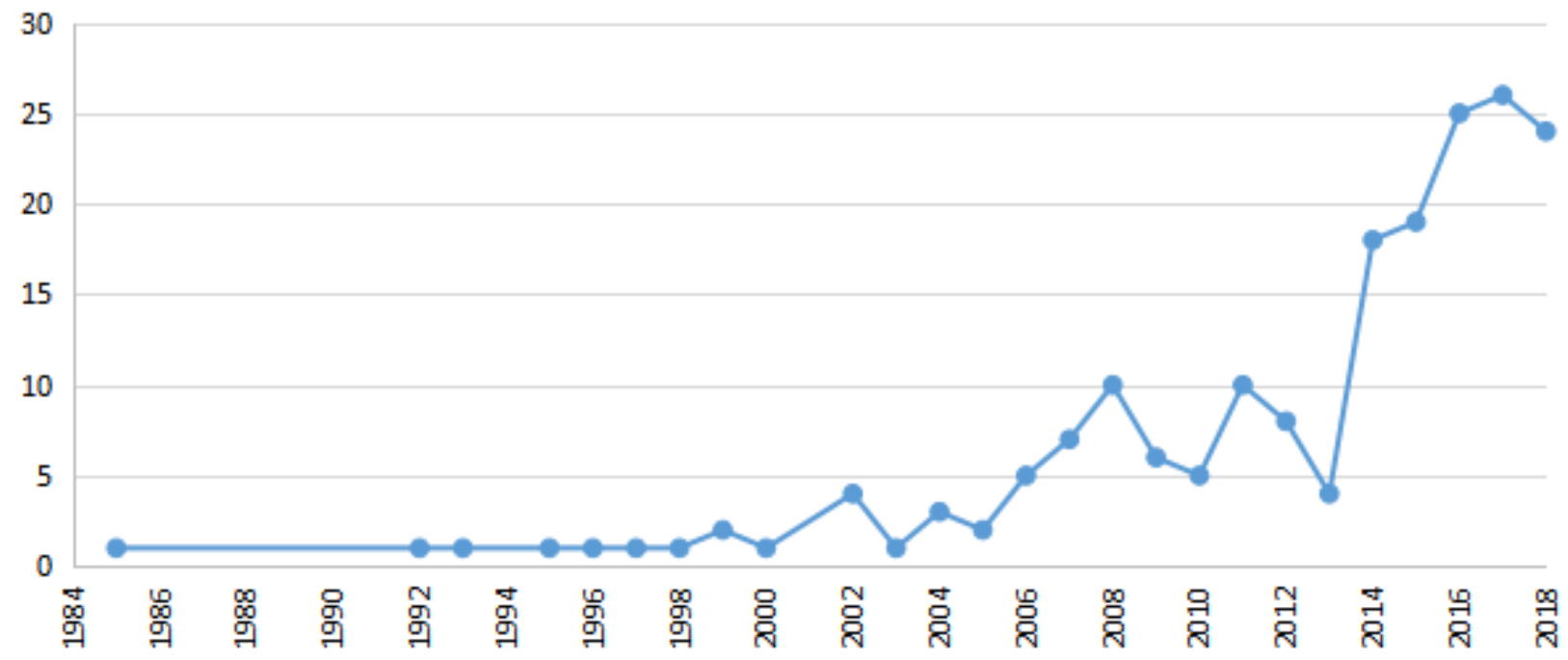

Fonte: Elaborado pelos autores deste artigo (2019)

A redução no número de patentes depositadas via PCT disponíveis para análise nesta base de dados durante o ano 2018, quando comparada aos anos 2016 e 2017, pode ser justificada pelo fato de elas serem mantidas em período de sigilo durante 18 meses contados da data de depósito ou da prioridade mais antiga e, por isso, a realização dos estudos de prospecção tecnológica podem sofrer uma limitação, já que um número considerável de depósitos não se encontra disponível em domínio público, sendo tal limitação já relatada em prospecção tecnológica anteriormente desenvolvida (ROCHA et al., 2014). Ressalta-se também que o período de sigilo encobre o que há de mais recente em termos de tecnologia nas diversas áreas do conhecimento, e por isso, parte do ano de 2018 pode não estar corretamente analisado.

Quanto à distribuição dos países com pedidos de depósitos, evidencia-se, através do Gráfico 2, que a tecnologia em estudo se apresenta concentrada, principalmente, nos países desenvolvidos, sendo liderada pelos Estados Unidos da América (EUA) com um total de 89 $(56,3 \%)$ pedidos de patentes. Entre os 16 países detentores dessa tecnologia, o Brasil ocupa o $11^{\circ}$ lugar, com $2(1,2 \%)$ depósitos, estando à frente de países como Áustria, Bélgica e República da Coréia, com apenas $1(0,6 \%)$ depósito de patente via PCT. Quanto à distribuição por continente, América (América do Norte 58\% e América do Sul 1\%) e Europa $(31,6 \%$ ) detêm a grande maioria dos pedidos de patentes referentes à utilização do T. castaneum como modelo experimental. Tal resultado demonstra o interesse de países em buscar modelos alternativos aos mamíferos, considerando-se que estes apresentam relevantes questões éticas e altos custos na 
manutenção, sendo substituídos por modelos invertebrados de baixo custo e alta efetividade, como insetos (INSUA et al., 2013).

Gráfico 2 - Ranking de países e continentes em função do número de depósitos via PCT para a busca de patentes na base PatentScope com as palavras-chave "Tribolium castaneum AND experimental model"

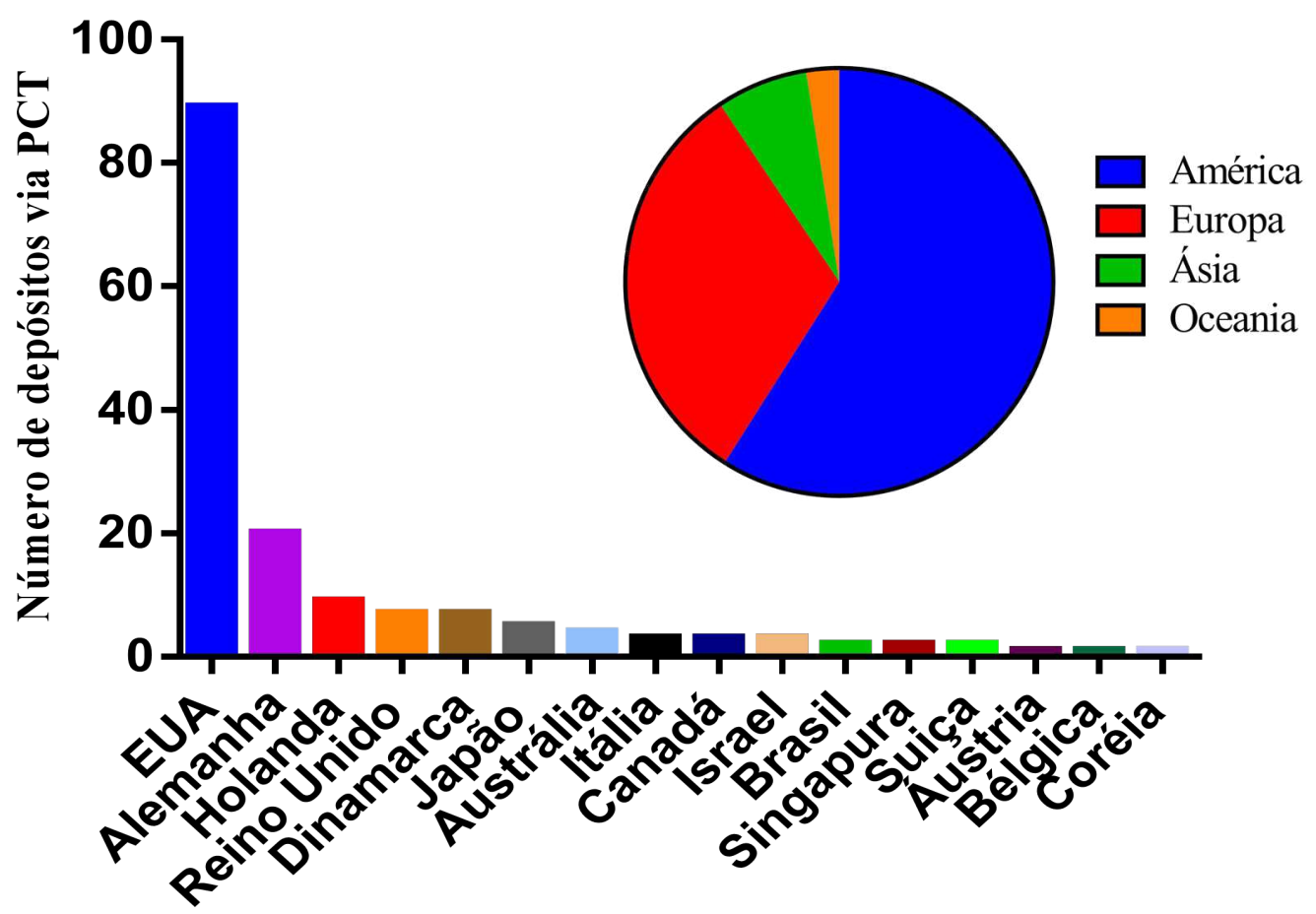

Fonte: Elaborado pelos autores deste artigo (2019)

Quanto ao país em que foi realizado o pedido de depósito destas patentes, o Gráfico 3 evidencia um cenário semelhante ao anterior. Os EUA é o país que mais realizou pedidos de depósitos $(55,9 \%)$ e também o país em que a maior parte destas patentes foram depositadas $(59,1 \%)$, demonstrando que grande parte da tecnologia empregada para utilização do Tribolium castaneum como modelo para estudos experimentais se encontra concentrada neste país.

Pelos dados do Gráfico 3, pode-se constatar também que 11,9\% destes pedidos foram depositados na European Patent Office (EPO - Organização Europeia de Patentes), uma organização intergovernamental formada pela aliança entre 27 Estados membros da União Europeia: Alemanha, Áustria, Bélgica, Bulgária, Chipre, Dinamarca, Eslováquia, Eslovénia, Espanha, Estónia, Finlândia, França, Grécia, Holanda, Hungria, Irlanda, Itália, Letónia, Lituânia, Luxemburgo, Malta, Polónia, Portugal, Roménia, Reino Unido, República Checa, Suécia, Suíça, Croácia, Mónaco, a ex-República Iugoslava da Macedônia, Noruega, Turquia, Albânia, Bósnia e Herzegovina, Sérvia e Montenegro. Dessa forma, um pedido de patente depositado na EPO oferece proteção para todos esses países citados. 
Gráfico 3 - Ranking de depósito de países e continentes em função do número de depósitos via PCT para a busca de patentes na base PatentScope com as palavras-chave "Tribolium castaneum AND experimental model"

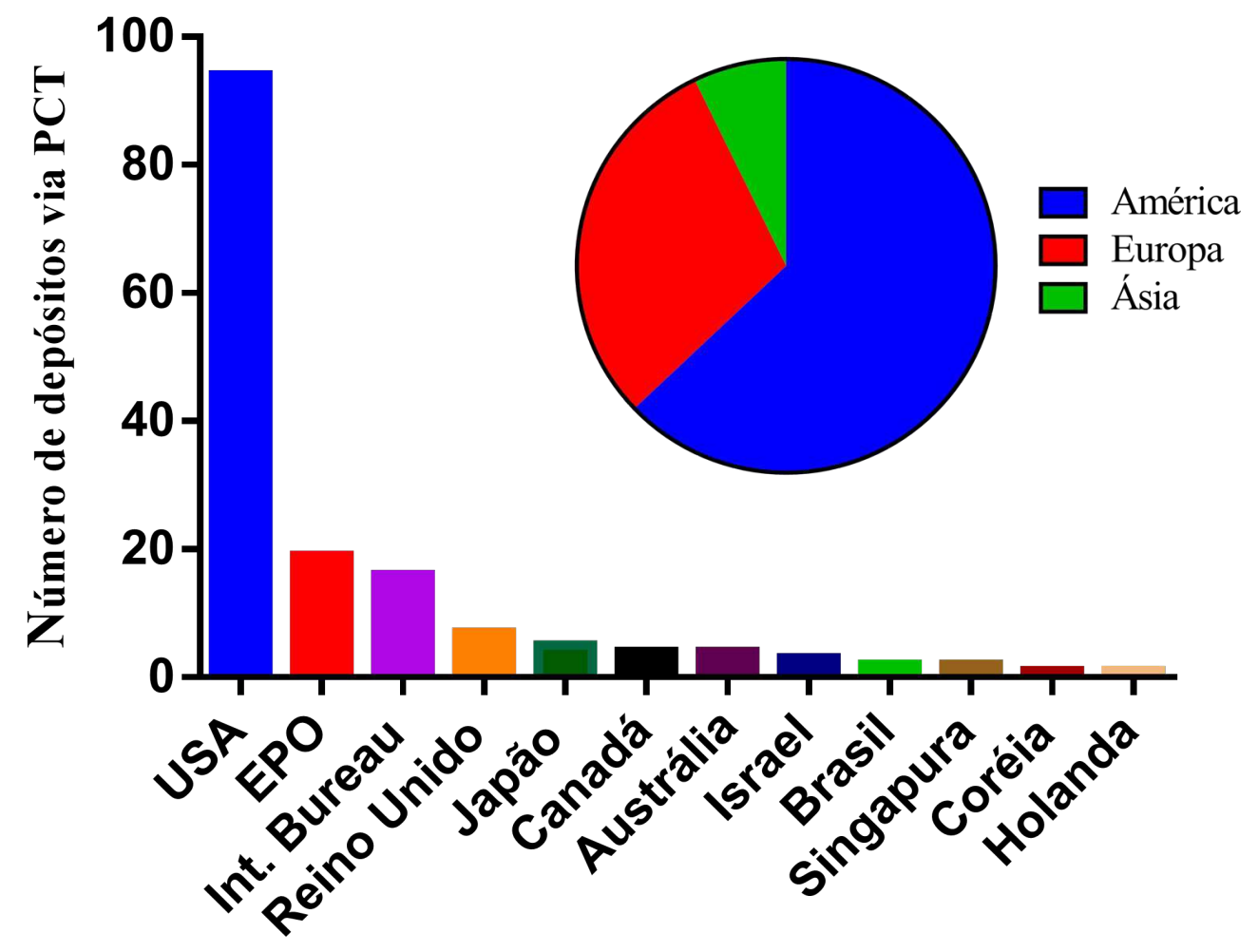

Fonte: Elaborado pelos autores deste artigo (2019)

Observa-se também que $10 \%$ dos pedidos de patentes são depositados na International Bureau, um departamento vinculado à Cooperação Europeia e Internacional da Agência de Gerenciamento de Projetos DLR, no Centro Aeroespacial Alemão. A International Bureau é uma organização de serviços que se dedica à promoção de pesquisa, educação e ciência da Alemanha. Dessa forma, constata-se que são os países desenvolvidos que detêm o processo de desenvolvimento e o direito legal sobre a exploração dessa tecnologia, sendo o continente Americano o detentor de $62,9 \%$ de seu uso.

Dos pedidos de patentes resgatados na base PatentScope, a grande maioria encontra-se classificada na Seção C - Química e Metalurgia (67,8\%), seguida por 42 pedidos na Seção A Necessidades Humanas (26,6\%), 8 pedidos na Seção G - Física (5\%) e apenas um pedido na Seção B - Operações de processamento; Transporte (0,6\%). Entre os 107 pedidos de depósitos na Seção C, ressalta-se que 61 patentes estão classificadas na especificação C12N (57\%), já descrita na Tabela 4. Em análise mais profunda, apresentada no Gráfico 4, observa-se que, entre esSas 61 patentes, 29 estão inseridas na especificação C12N 15/82 (47,5\%), porém voltada para utilização em células vegetais. A análise dos códigos e resumos das patentes revelou que tais pedidos se referem, principalmente, a repelentes de pestes/controle de pragas, o que é explicado pelo fato de o Tribolium castaneum ser uma das principais pragas de grãos armazenados com distribuição mundial, considerado uma praga de produtos armazenados de grande importância econômica (FARONI; FRABETTI, 2009). 
Gráfico 4 - Classificação IPC dos depósitos de pedidos de patentes via PCT na base PatentScope com as palavras-chave "Tribolium castaneum AND experimental model"
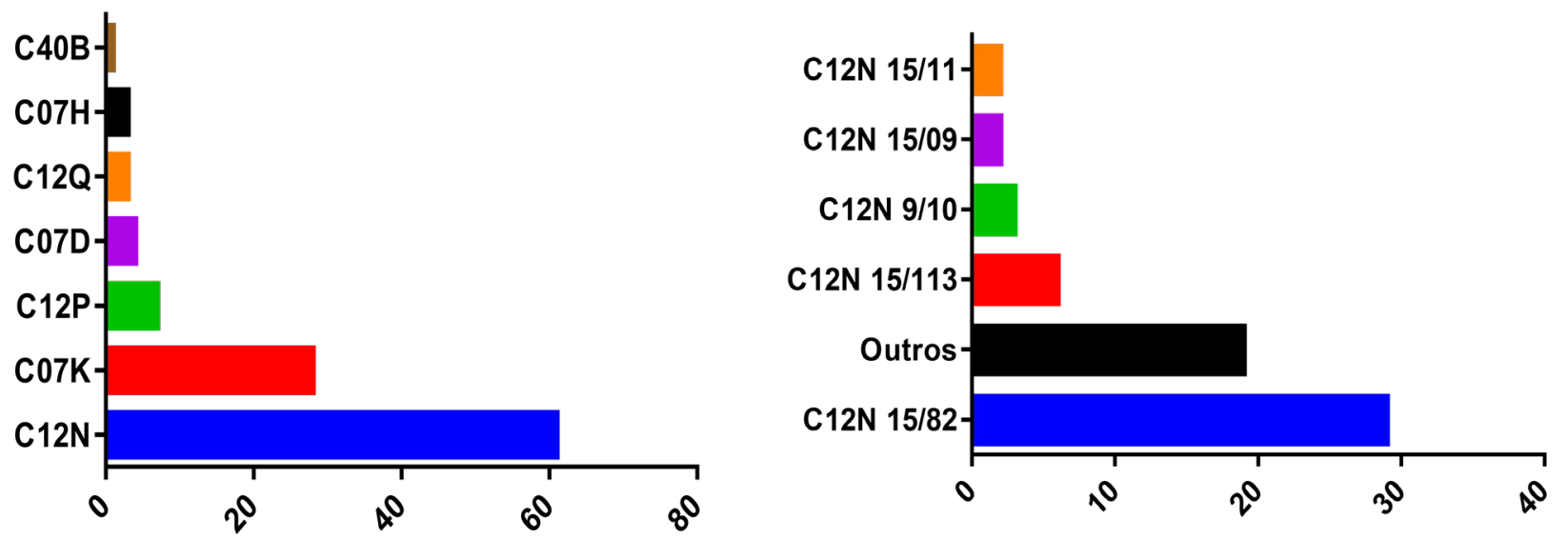

Fonte: Elaborado pelos autores deste artigo (2019)

Os resultados obtidos com a busca de patentes depositadas via PCT da base de dados PatentScope indicam que, apesar de vários pedidos reivindicarem a utilização do Tribolium castaneum como modelo experimental, nenhum se refere ao estudo do metabolismo de lipídeos e carboidratos, sendo esta uma área tecnológica pouco explorada e potencialmente útil para novas pesquisas.

\subsection{Análise das patentes depositadas na base de dados Espacenet}

O Espacenet é uma base mundial de acesso livre, usualmente utilizada para prospecção, e que abrange cerca de 90 milhões de documentos de patente depositadas em mais de 18 países da América Latina e na Espanha. O resultado da busca nesta base foi apresentado na Tabela 3 e será discutido em dois momentos: com os resultados do termo "Modelo experimental", onde foram recuperadas 66 patentes, mas sem especificidade para o Tribolium castaneum; e com os resultados obtidos a partir da palavra-chave "Tribolium castaneum", com apenas cinco pedidos de patentes.

O Gráfico 5 ilustra a análise temporal dos pedidos de depositados recuperados através do termo "Modelo experimental", com a primeira reivindicação em 1997, porém, com pico em 2015 (oito pedidos de depósitos), reafirmando um avanço tecnológico/metodológico na pesquisa do objeto em específico e/ou um crescimento no interesse de estudos nesta área. Destaca-se também que o baixo número de patentes depositadas no ano 2016 (dois pedidos) pode não refletir a realidade devido ao período de 18 meses de sigilo. 
Gráfico 5 - Número de patentes por ano na base Espacenet com a palavra-chave "modelo experimental"

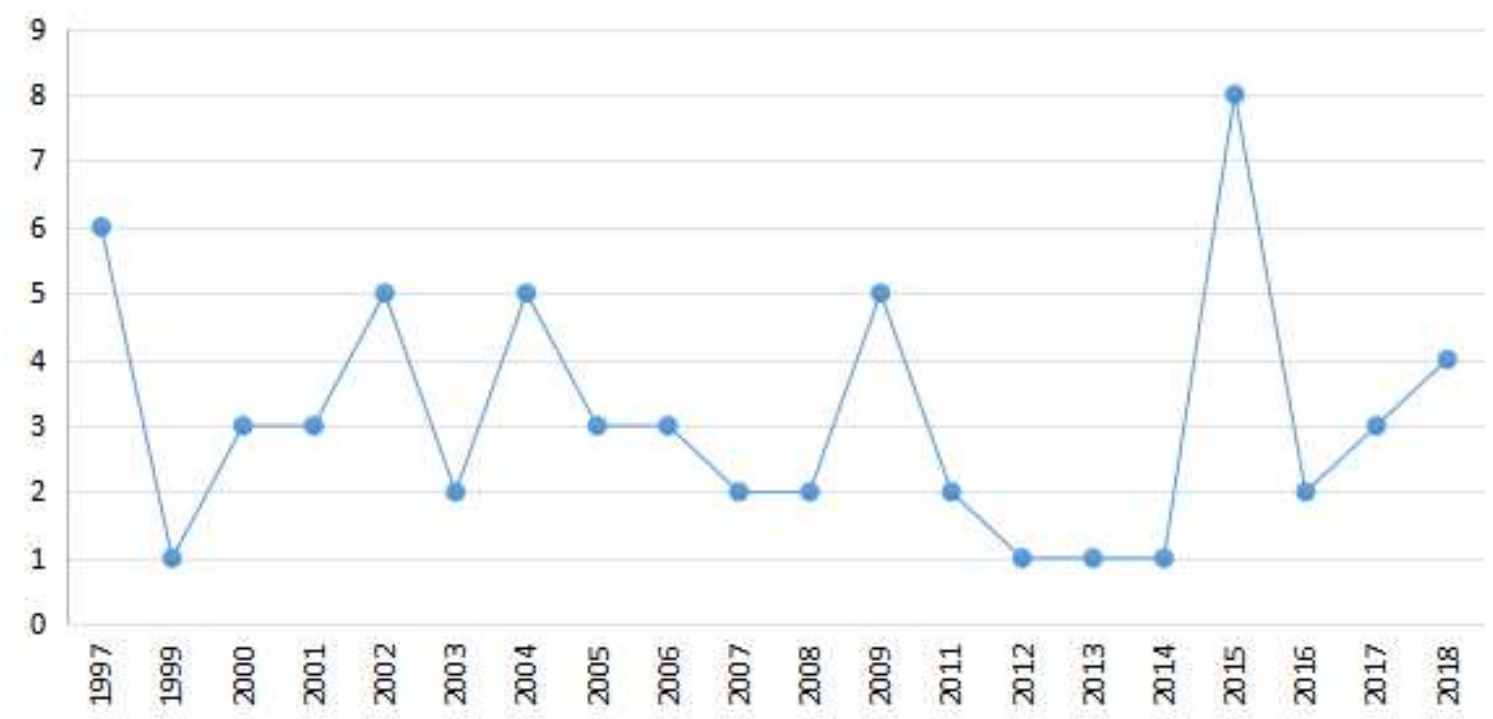

Fonte: Elaborado pelos autores deste artigo (2019)

Dos 66 pedidos de patentes recuperados nesta base de dados com a palavra-chave em destaque, 18 (31,5\%) foram requeridos pelo Brasil, seguido por 11 (19,2\%) pedidos de depósitos feitos pelos EUA, como demonstra o Gráfico 6. A análise mostra que a maioria dos países requerentes pertencem ao continente Americano (63,3\%), e desses pedidos, 58,3\% foram requeridos por países da América do Sul (Brasil 18, Argentina 2 e Cuba 1 pedido de depósito), 30,5\% pelos EUA e 11,1\% pelo México.

Dos 18 pedidos de depósitos de patentes requeridos pelo Brasil, 13 (72,3\%) foram realizados por Instituições Públicas de Ensino (Estaduais e Federais) e órgãos de fomento à pesquisa, $e$ apenas cinco $(27,7 \%)$ foram requeridos por pessoas físicas (não institucionais). Nota-se também que cinco $(38,3 \%)$ dos pedidos de depósitos realizados pelas instituições públicas brasileiras ocorreram em 2015, corroborando com a suposição anterior de que algum fato incentivou o aumento das pesquisas nesta área do conhecimento durante aquele período. Ressalta-se ainda o grande número de pedidos de patentes requeridos por instituições públicas brasileiras, indicando que, mesmo diante do cenário de (sub)financiamento das pesquisas públicas, as universidades ainda são promotoras do desenvolvimento inovador e tecnológico no Brasil.

Quanto aos países de depósito dos pedidos de patentes, observa-se, por meio do Gráfico 7, que o Brasil, além de ser o principal país requerente, também é o país em que a maior parte das patentes analisadas foram depositadas (25 depósitos - 43,8\%). Os EUA são responsáveis pelo pedido de $19,2 \%$ das patentes que envolvem "modelos experimentais" depositadas no Brasil, o que demonstra que, além de ser um grande produtor dessa tecnologia, o Brasil também é um país com alto potencial para o desenvolvimento de tais métodos e utilizações. 
Gráfico 6 - Ranking de países e continentes requerentes das patentes em função do número de depósitos para a busca na base Espacenet com a palavra-chave "modelo experimental"

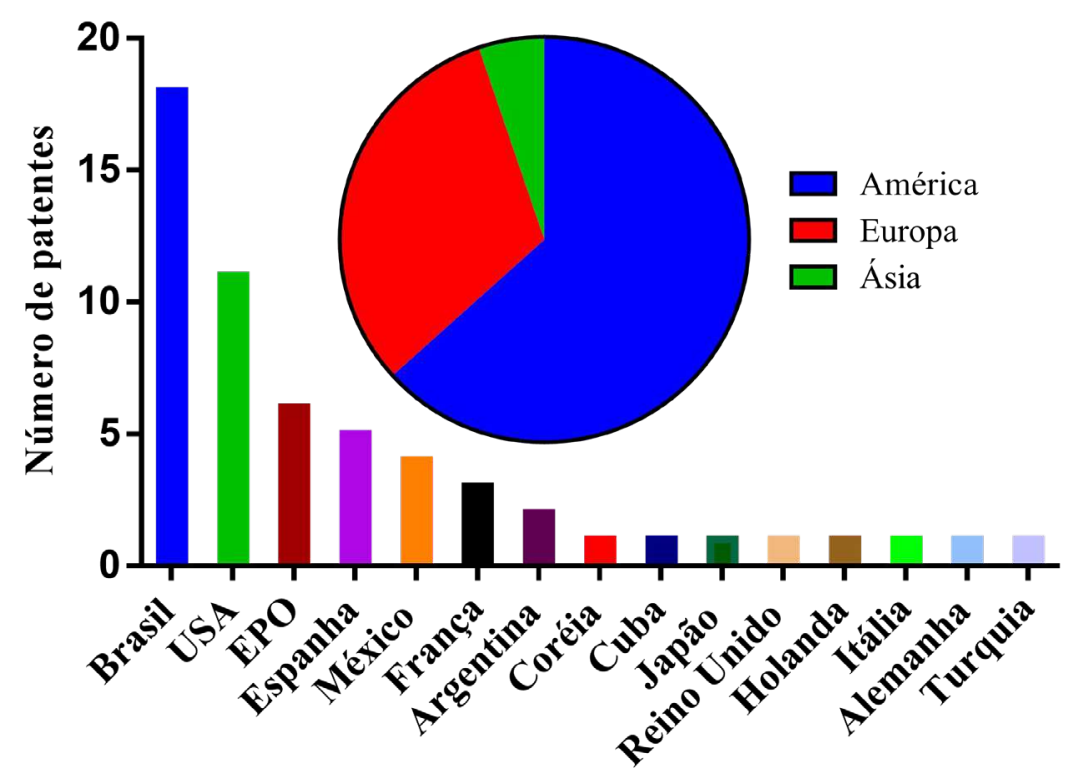

Fonte: Elaborado pelos autores deste artigo (2019)

Gráfico 7 - Ranking de países e continentes de depósito em função do número de patentes para a busca na base Espacenet com a palavra-chave "modelo experimental"

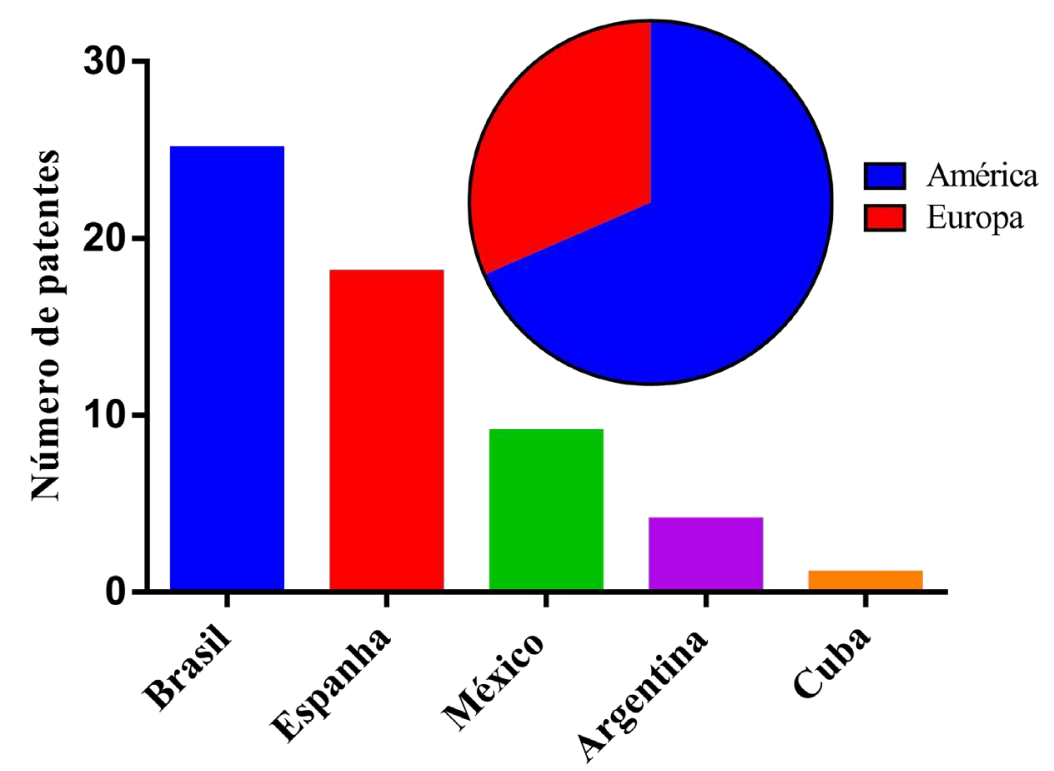

Fonte: Elaborado pelos autores deste artigo (2019)

A distribuição dos pedidos de patentes por local de depósito evidencia que a tecnologia produzida, principalmente, por países desenvolvidos foi registrada em países em desenvolvimento, concentrados no continente Americano, sendo nove pedidos (15,7\%) depositados na América Latina (México) e 30 (52,6\%) depositados na América do Sul, contemplando 25 depósitos (43,8\%) no Brasil, 4 (7\%) na Argentina e 1 (1,7\%) em Cuba.

Entre os pedidos recuperados, $34(59,6 \%)$ estão inseridos na classificação IPC na Seção A - Necessidades Humanas, enquanto apenas três $(5,2 \%)$ pedidos estão na Seção C - Química; Metalurgia, conforme mostra o Gráfico 8. A maior dispersão das classificações desses pedidos se deve a não especificação de tais Modelos Experimentais. Como esta prospecção se debruça sobre a 
classificação $\mathbf{C 1 2 N}$ 15/06, é importante um olhar atento aos três pedidos de depósitos classificados na Seção C, porém, constata-se que nenhuma destas patentes foi requerida na classificação C12: duas estão no grupo C07 (Química Orgânica) e um no grupo C09 (Corantes; Tintas; Polidores; Resinas Naturais; Adesivos; Aplicações de Materiais não abrangidos em outros locais).

Gráfico 8 - Distribuição dos pedidos de patentes por Seção na classificação IPC

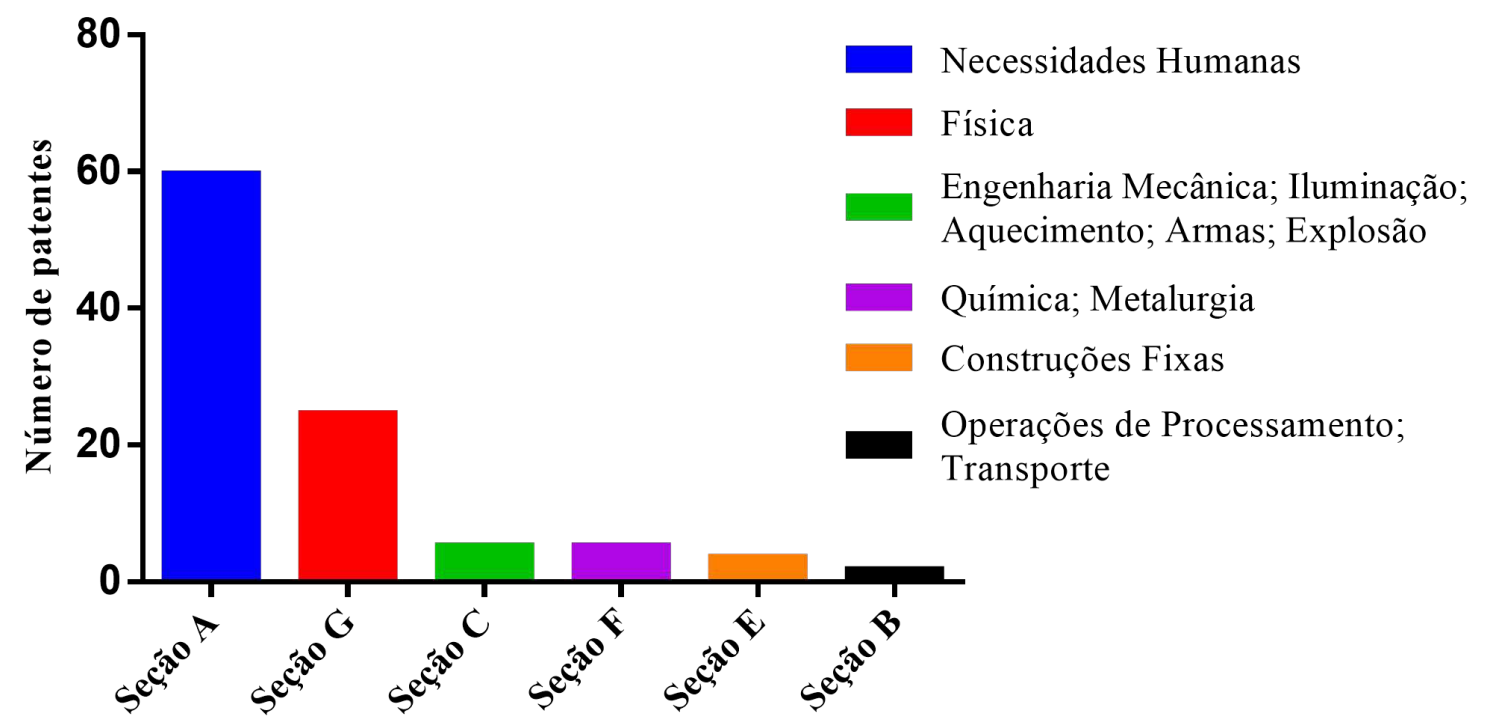

Fonte: Elaborado pelos autores deste artigo (2019)

A pesquisa na base de dados Espacenet utilizando-se as palavras-chave "Tribolium castaneum", como demonstrado na Tabela 3, apresentou apenas cinco resultados. Desses resultados, dois (40\%) pedidos de depósitos foram requeridos em 1997 pela Monsanto Technology LLC, dos EUA, uma companhia americana especializada no desenvolvimento de tecnologia agropecuária. Porém, um pedido foi depositado na Argentina (composição e método para preparar um inseticida) e outro na Espanha (composições de Cryet29 de Bacillus thuringiensis tóxico para espécies de insetos coleópteros). Outro pedido de depósito, realizado em 2008 , foi requerido pela Suntory Holdings LTD, uma grande empresa japonesa produtora de bebidas, especialmente alcoólicas. Esta empresa desenvolveu e requereu os direitos sobre os métodos para identificação dos hábitats de insetos na Espanha.

Além das proteções citadas, destaca-se o pedido realizado em 2017 pela Universidade de Valência, Espanha, que se refere a um peptídeo derivado da defensina 3 do Tribolium castaneum e suas composições farmacêuticas para uso como antimicrobiano no tratamento de infecções causadas por bactérias e fungos e no tratamento de câncer, em particular, o câncer de mama. O último pedido de patente obtido nesta busca, foi solicitado pela Universidade Autonoma Chapingo, do México, em 2018, que reivindica uma composição de diluições agro-homeopáticas dinamizadas feitas de pragas e doenças da cultura do milho para a proteção da cultura do milho de maneira holística.

A análise dos pedidos de depósitos de patentes obtidos na base de dados Espacenet, tanto com a utilização das palavras-chave "modelo experimental" quanto "Tribolium castaneum", indica que não há pedido de proteção que se refere à tecnologia analisada nesta prospecção, sendo este um vasto campo a ser explorado, considerando-se que este inseto apresenta carac- 
terísticas favoráveis, como rápida reprodução, alta fecundidade, intervalos curtos de geração, baixos custos de manutenção, aspectos éticos aceitáveis, genoma acessível em banco de dados, além das sequências de genes apresentarem intensa relação de homologia com outras espécies, incluindo humanos.

\subsection{Análise de artigos publicados na base PubMed}

Para a análise dos artigos publicados na base de dados PubMed acerca da utilização do Tribolium castaneum como modelo experimental para estudo do metabolismo de lipídeos e carboidratos, utilizou-se a combinação das palavras-chave "Tribolium castaneum AND experimental model", recuperando-se um total de 130 artigos, já demonstrados na Tabela 2.

Em comparação aos pedidos de patentes via PCT na base PatentScope, utilizando-se as mesmas palavras-chave, a evolução anual do número de artigos publicados (Gráfico 9) apresenta um panorama mais disperso, com o primeiro artigo publicado em 1966, antecedendo ao primeiro pedido de depósito de patente, que ocorreu em 1985 (Gráfico 1). Em 2010 e 2017 ocorreram picos nas publicações, com 11 artigos lançados, pesquisas estas que podem ter servido de base para as patentes requeridas, as quais obtiveram auge entre 2014 e 2017.

Gráfico 9 - Número de artigos publicados por ano na base de dados PubMed com as palavras-chave "Tribolium castaneum AND experimental model"

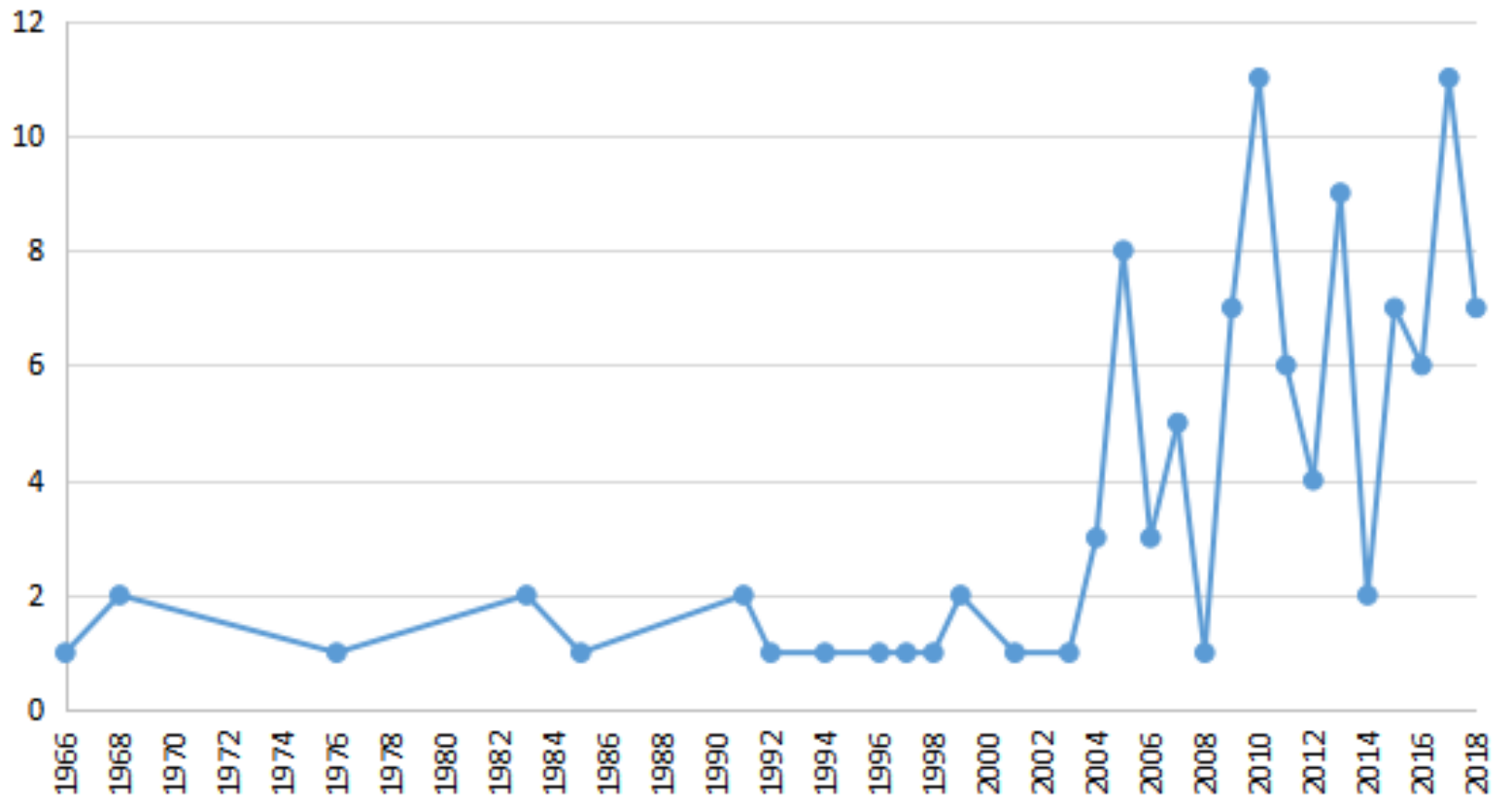

Fonte: Elaborado pelos autores deste artigo (2019)

Quanto ao país de filiação do primeiro autor dos artigos (Gráfico 10), observou-se que há similaridade entre os dois países que mais publicam e os que mais requerem o pedido de patentes na base de dados PatentScope (Gráfico 2), sendo o primeiro lugar ocupado pelos EUA, com 48 (43,2\%) artigos publicados, seguido da Alemanha, com 13 (11,7\%) publicações. 
Gráfico 10 - Ranking dos artigos científicos publicados na base PubMed por país do primeiro autor com busca pelas palavras-chave "Tribolium castaneum AND experimental model"

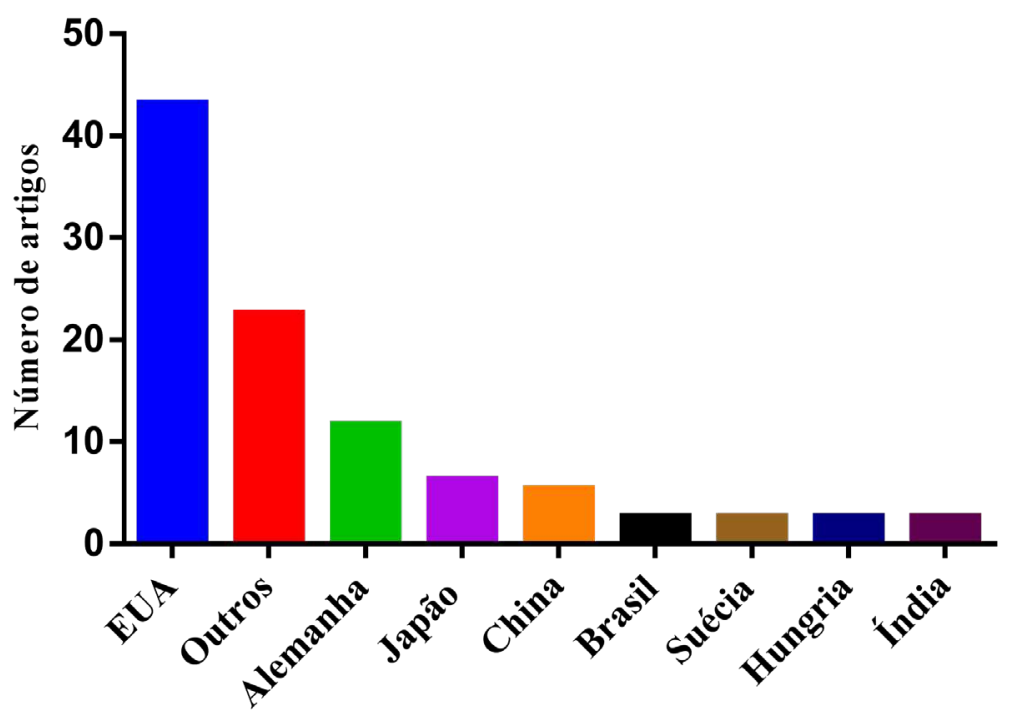

Fonte: Elaborado pelos autores deste artigo (2019)

No ranking das publicações, o Brasil tem três $(2,7 \%)$ artigos publicados e divide o quinto lugar com países como Suécia, Hungria e Índia, apresentando melhor resultado quando comparado ao número de depósitos de patentes (dois pedidos $-1,2 \%$ ), pois apresenta mais artigos do que alguns países que apresentaram maior número de patentes, como Holanda, Reino Unido, Dinamarca, Austrália, Itália, Canadá e Israel. Essa análise permite inferir que, tanto na área de estudo dessa prospecção quanto em outras (OLIVEIRA et al., 2017; SOARES; DRUZIAN; LOBATO, 2018; BENEVENUTI; NEI PEREIRA, 2016), a produção científica brasileira continua apresentando perfil técnico, sem uma correspondente produção tecnológica e sua proteção intelectual por meio de depósitos de patentes.

Todos os artigos recuperados nesta busca são provenientes de pesquisas realizadas em instituições de ensino. As três publicações brasileiras foram desenvolvidas em Universidades Públicas da Região Sul (Universidade Federal de Pelotas, Rio Grande do Sul, e Universidade Estadual de Maringá, Paraná) e da Região Sudeste (Universidade Federal do ABC, Santo André, São Paulo) do país, o que demonstra que a utilização do Tribolium castaneum como modelo experimental é uma tecnologia que ainda não está difundida em todo país, sendo esta uma grande lacuna a ser preenchida.

\section{Considerações Finais}

A partir da análise das patentes depositadas entre os anos de 1985 e 2017, pode-se concluir que existe uma tendência ao crescimento de depósitos envolvendo a utilização do Tribolium castaneum como modelo experimental.

A análise do cenário mundial, por meio de busca na base de dados PatentScope, constata que são os países desenvolvidos que detêm a tecnologia patenteada e onde ela se origina. Esses países são Estados Unidos da América e Alemanha, estando o Brasil apenas na $11^{a}$ posição. Em um contexto mais restrito, analisado por meio de busca na base Espacenet, o Brasil ocupa 
o primeiro lugar no ranking dos pedidos de patentes, evidenciando que tais depósitos são protegidos, principalmente, no próprio país requisitante.

Cabe ressaltar sobre a limitação dessa prospecção no que se refere aos depósitos de patentes requeridos a partir de 2016, pois um número considerável de patentes não se encontra ainda disponível em domínio público, visto que há proteção de sigilo de 18 meses.

Constata-se, por meio de todas as análises realizadas nas bases de dados PatentScope, Espacenet e PubMed, que não há depósito de pedido de patente que reivindique a tecnologia objeto dessa prospecção ou artigo científico que explicite o seu desenvolvimento. Portanto, a utilização do Tribolium castaneum como modelo experimental (para estudo do metabolismo de lipídeos e carboidratos) constitui uma área tecnológica pouco explorada e potencialmente útil para novas pesquisas e produtos.

\section{Referências}

AKAM, M. Hox and Hom: Homologous gene clusters in insects and vertebrates. Cell, [S.l.], 1989.

BENEVENUTI, C. S. J.; PEREIRA JÚNIOR, N. Prospecção tecnológica da produção de ácido lático no contexto de biorrefinaria: Tendências e oportunidades. Espacios, [S.l.], v. 37, n. 23, p. 10, 2016.

BOMAN, H. G.; HULTMARK, D. Cell-free immunity in insects. Annu. Rev. Microbiol., [S.l.], n. 41, p. 103-126, 1987. DOI:10.1146/annurev.mi.41.100187.000535.

CHOWANSKI, S. et al. Insect peptides-perspectives in human diseases treatment. Current Medicinal Chemistry, [S.l.], v. 24, n. 29 p. 3.116-3.152, 2017.

CISNE, J. L. Trilobites and the Origen of Arthropods. Science, [S.I.], n. 186, p. 13-18, 1974.

DEMIR, E.; DICKSON, B. J. Fruitless splicing specifies male courtship behavior in Drosophila. Cell, [S.l.], v. 121, p. 785-794, 2005.

DÖNITZ, J. et al. Tron: An Anatomical Ontology for the Beetle Tribolium castaneum. Plos One, [S.l.], v. 8, p. 1-8, 2013.

FARONI, L. R.; FRABETTI, D. R. Principais pragas de grãos armazenados. Net, Minas Gerais, 2009. Disponível em: http://www.centreinar.org.br. Acesso em: 10 set. 2019.

FISHER, R. A. On the Evidence Against the Chemical Induction of Melanism in Lepidoptera. B Proceedings of the Royal Society of London, [S.I.], n. 102, p. 407-416, 1933.

GRILLO, L. A. M.; MAJEROWICZ, D.; GONDIM, K. C. Lipid metabolism in Rhodnius prolixus (Hemiptera : Reduviidae ): Role of a midgut triacylglycerol-lipase. Insect Biochemistry and Molecular Biology, [S.l.], n. 1.994, 2007.

GRÜNWALD, S.; STELLZIG, J.; ADAM, I. V. et al. Longevity in the red flour beetle Tribolium castaneum is enhanced by broccoli and depends on nrf-2, jnk-1 and foxo-1 homologous genes.

Genes \& Nutrition, [S.I.], v. 8, p. 438-448, 2013.

HOY, M. A. Insect Molecular Genetics: an introduction to principles and applications. São Paulo: Elsevier, 2003. 
INSUA, J. L. et al. Modeling Klebsiella pneumoniae pathogenesis by infection of the wax moth Galleria mellonella. Infect Immun., [S.l.], v. 81, n. 10, p. 3.552-3.565, Oct. 2013. DOI: 10.1128/ IAI.00391-13.

KEILIN, D. The History of Cell Respiration and Cytochrome. Cambridge, UK: Cambridge University Press, 1966.

MARANHÃO, Z. G. Entomologia Geral. 2. ed. São Paulo: Nobel, 1977.

OLIVEIRA, J. M. S. et al. Uso de própolis no desenvolvimento de resinas dentárias: um estudo prospectivo. Cadernos de Prospecção, Salvador, v. 10, n. 2, p. 285-299, abr.-jun. 2017.

RICHARDS, S. et al. Tribolium genome sequencing consortium. The genome of the model beetle and pest Tribolium castaneum. Nature, [S.l.], v. 452, p. 949-955, 2008.

ROCHA, I. S. et al. Prospecção tecnológica com o enfoque na produção e preparações de alimentos com aroma e sabor de café e cacau. Revista GEINTEC, São Cristóvão, SE, v. 4, n. 4, p. 1.4181.425, 2014. DOI: 10.7198/S2237-0722201400040015.

ROTH, T. F.; PORTER, R. R. Yolk uptake in the oocyte of the mosquite Aedes aegypti. J. Cell. Biol., [S.I.], n. 20, p. 313-332, 1964.

SAKAI, T; KITAMOTO, T. Differential roles of two major brain structures, mushroom bodies and central complex, for Drosophila male courtship behavior. Journal of Neurobiology, [S.I.], v. 66, p. 821-834, 2006.

SCHELLER, K.; KARLSON, P. Effects of ecdysteroids on RNA synthesis of fat body cells in Calliphora vicina. J. Insect Physiol., [S.l.], n. 23, p. 285-291, 1977.

SOARES, C. C.; DRUZIAN, J. I.; LOBATO, A. K. C. L. Estudo prospectivo de patentes relacionadas a utilização do Bacillus subtilis em bioprocessos. Cadernos de Prospecção, Salvador, v. 11, Edição Especial, p. 295-303, abr.-jun. 2018.

TELFER, W. H. The route of entry and localization of blood proteins in the oocytes of saturniid moths. J. Biophys. Biochem. Cytol., [S.l.], n. 9, p. 747-754, 1961.

TELFER, W. H. The selective accumulation of blood proteins in the oocytes of saturniid moths. Biol. Bull., [S.I.], n. 119, p. 338-346, 1960.

\section{Sobre os Autores}

\section{Meirielly Kellya Holanda Silva}

E-mail: meirielly.holanda@hotmail.com

Doutorado em Biotecnologia em Saúde pela Rede Nordeste de Biotecnologia (RENORBIO/UFAL) em 2020. http://lattes.cnpq.br/2696354286276464.

Endereço profissional: Universidade Federal de Alagoas, Campus Arapiraca, Av. Manoel Severino Barbosa, Bom Sucesso, Arapiraca, AL. CEP: 57309-005. 


\section{Mariana Macêdo Costa Batalha}

E-mail: marianamcbatalha@gmail.com

Doutora em Bioquímica e Biologia Molecular pelo Programa Multicêntrico em Bioquímica e Biologia Molecular nas unidades da UFAL e UFRJ em 2020. http://lattes.cnpq.br/3925546334736310.

Endereço profissional: Laboratório de Bioquímica Metabólica da Universidade Federal de Alagoas, Av. Lourival Melo Mota, s/n, Tabuleiro do Martins, Maceió, AL. CEP: 57072-970.

\section{Camila Braga Dornelas}

E-mail: dornelascb@yahoo.com.br

Pós-Doutorado na área de Nanotecnologia Farmacêutica pela Universidade Federal de Pernambuco (UFPE) em 2013. http://lattes.cnpq.br/9384424638219962.

Endereço profissional: Instituto de Ciências Farmacêuticas da Universidade Federal de Alagoas, Av. Principal da UFAL, Cidade Universitária, Maceió, AL. CEP:

\section{Luciano Aparecido Meireles Grillo}

E-mail: lucianomeirelesgrillo@gmail.com

Pós-doutorado em Genômica Funcional pela Universidade Federal do Rio de janeiro (UFRJ) em 2018. http:// lattes.cnpq.br/5456839333813472.

Endereço profissional: Instituto de Ciências Farmacêuticas da Universidade Federal de Alagoas, Av. Principal da UFAL, Cidade Universitária, Maceió, AL. CEP: 